Article available at http://www.parasite-journal.org or http://dx.doi.org/10.1051/parasite/1998051087

\title{
Age grading ANOPHELES ARABIENSIS: theIR GORGING AND SURVIVING RESPONSES USING A MEMBRANE FEEDING SYSTEM
}

\author{
ROBERT V.*
}

\begin{abstract}
Summary :
Literature on artificial membrane feeding has traditionally supported the notion that mosquitoes have to be enough old to present a high gorging rate and enough young to present a high surviving rate. In order to know the best mosquito age to perform a Plasmodium sp. experimental infection revealed by oocyst examination, Anopheles arabiensis of known ages were fed on baudruche membrane with fresh human blood thermostated at $37^{\circ} \mathrm{C}$. The response was evaluated in term of gorging after ten minutes in contact with the membrane feeder and, for engorged females, in term of survival eight days after the engorgement. Two strains of mosquitoes were used, one wild, collected at larval stages in the city of Dakar and the other, originating from the same place but reared in our insectary since three years. The two strains showed their highest gorging rate at $3-4$ days after emergence $139.4 \%$ for the wild strain and $63.3 \%$ for the insectary strain). The survival rate of the wild strain was highest at 2-3-4 days after emergence $(64,8 \%)$ and those of the insectary strain at four days $(65.6 \%)$. In conclusion, the gorging mosquitoes would have to be aged of 3-4 days after emergence for the wild strain and of four days for the insectary strain in order to obtain eight days after the engorging the best output of fed and surviving mosquitoes.
\end{abstract}

KEY WORDS : Anopheles arabiensis, age of the mosquitoes, membrane feeder, gorging rate, surviving rate, insectary

\section{INTRODUCTION}

\section{A} wide variety of membrane feeders have been reported in the literature for use with bloodsucking insects (Wade, 1976). For mosquito feeding the apparatus proposed by Rutledge et al. (1964) is often used, its simplicity being an important advantage. The factors potentially involved in the feeding response of mosquitoes are very numerous: the type of meal proposed, type of membrane, mosquito species, number of mosquitoes per cage (Rutledge $e t$

* ORSTOM, Laboratoire de Paludologie, BP 1386, Dakar, Sénégal. Tel : (221) 8320962 - Fax : (221) 8321675.

Email : Vincent.Robert@orstom.sn
Résumé : IMPORTANCE DE L'ÂGE D'ANOPHELES ARABIENSIS POUR SON GORGEMENT SUR MEMBRANE ET POUR SA SURVIE

La littérature sur les repas avec membrane artificielle rapporte habituellement que les moustiques doivent être assez vieux pour présenter un haut taux de gorgement et assez jeunes pour présenter un haut taux de survie. Dans le but de connaitre l'âge optimum des moustiques pour effectuer une infection expérimentale par Plasmodium sp. révélée par le comptage des oocystes, des Anopheles arabiensis d'âges connus ont été gorgés sur membrane de baudruche avec du sang humain frais thermostaté à $37^{\circ} \mathrm{C}$. Le gorgement a été évalué après dix minutes au contact de la membrane artificielle et, pour les femelles gorgées, la survie a été évaluée huit jours après le gorgement. Deux souches de moustiques ont été utilisées: la première, sauvage, a été collectée aux stades larvaires dans la ville de Dakar et la seconde, originaire de la même localité a été élevée dans notre insectarium pendant trois ans. Les deux souches ont montré un taux de gorgement maximum à $3-4$ jours après l'émergence $139,4 \%$ pour la souche sauvage et $63,3 \%$ pour la souche d'insectarium). Le taux de survie de la souche sauvage a été maximum à 2-3-4 jours après l'émergence $(64,8 \%)$ et celui de la souche d'insectarium à quatre jours $(65,5 \%)$. En conclusion, les moustiques à gorger doivent être âgés de trois ou de quatre jours pour la souche sauvage et de quatre jours pour la souche d'insectarium afin d'obtenir le meilleur rendement en moustiques gorgés qui survivent huit jours après le repas sur membrane.

MOTS CLÉS : Anopheles arabiensis, âge des moustiques, repas sur membrane, taux de gorgement, taux de survie, insectarium.

al., 1964), surface of membrane (Ponnudurai et al., 1989), temperature (Cosgrove \& Wood, 1995) etc. Surprisingly the age of mosquitoes which is potentially acting as one of these factors is poorly documented. Most of the authors indicate the age of mosquitoes used but without to argue their choice about mosquito age. It is a general practice to optimize survival rates in most vector competence experiments by selecting female mosquitoes that are 2-4 days old for feeding experiments whenever possible. If only older females are available, it is widely recognized that survival rates are going to be less than optimal. On the other hand, if only younger females are available, the gorging rates will be very low, even when mosquitoes have been starved without access to sucrose solution.

In experiments on malaria transmission as routinely performed in our insectary we measured the passage 
of parasite from man to mosquitoes by microscopical count of oocysts, the parasite stage on the stomach wall, at day 8 after experimental infection when the oocyst are big enough to be easily identified. For that reason we observed the survival rate eight days after the membrane feeding.

The aim of this study was to investigate the effect of the age of gorging mosquitoes upon the engorgement using human blood and a membrane system, and upon the survival of engorged females. A practical conclusion concerning the best choice for mosquito age in Plasmodium sp. experimental infection, is attempted.

\section{MATERIALS AND METHODS}

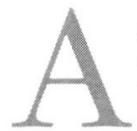

strain of Anopheles arabiensis, caught in November 1993 in Colobane, an area in Dakar, Senegal, was maintained under insectary conditions and adapted to feed on a membrane. The experiment exposed later took place between September and December 1996. Considering each mean generation spend 14 days (Diop, 1995), therefore our experiments used the $144^{\text {th }}-160^{\text {th }}$ generations bread at the insectary. Temperature was kept between 27 and $29^{\circ} \mathrm{C}$, relative humidity between 70 and $90 \%$ and $11 \mathrm{~h}$ day/13 h night cycle beginning at $07.00 \mathrm{~h}$. Larvae were daily fed with Tetra Baby Fish Food $L^{\circledR}$. Pupae were collected in cups using plastic pipettes and placed in cages where emergence occurred. Adults had permanent access to a $3 \%$ sucrose solution. Ordinary, from two days after emergence Guinea pigs were daily proposed to mosquitoes for a blood feeding but not for mosquitoes which had to be engorged in the next forty hours through membrane feeding system. A wild strain of the same anopheline species was collected each two days at larval stages in Colobane from the same permanent breading places from which the insectary strains was originated. Larvae were brought to the insectary where they received the same processing than insectary strain. Emerging mosquitoes were used for membrane feeding experiments.
We used batches of mosquitoes homogenous for their age, varying from two to 13 days after emergence. We did not used mosquitoes aged of one day after emergence because of their obvious low ability to become fully fed.

At $07.00 \mathrm{~h}$ batches of female mosquitoes (mean \pm standard deviation: $58.8 \pm 4.8$; ranges : 40-74) were placed in plastic coated board cups for food contact, with mosquito net attached to the horizontal top of the cup with an elastic band. In this cup mosquitoes had no access to sucrose solution. The volume available for mosquitoes was $220 \mathrm{ml}$ and the net surface available for mosquitoes was $38.5 \mathrm{~cm}^{2}$. All experiments were carried out between 10,00 and 15,00 h. Venous blood of human volunteers was collected into sterile heparinized vacutainer tubes. A membrane feeder with surface area of $15.9 \mathrm{~cm}^{2}$ as describe by Ponnudurai et al. (1989), thermostated at $37^{\circ} \mathrm{C}$, was quickly filled with $6 \mathrm{ml}$ of blood using a sterile syringe and the mosquitoes were allowed to take blood through a baudruche membrane during ten minutes in a dark place. Fully fed mosquitoes were counted and placed into a cage with permanent access to a $3 \%$ sucrose solution. After eight days, surviving mosquitoes were counted. Percentages of engorged mosquitoes and percentages of surviving mosquitoes were compared using a $\chi^{2}$ test of Pearson.

\section{RESULTS}

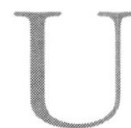

sing the membrane feeding system the engorging rate was dependant of the age of mosquitoes (Table I and Fig. 1). For the wild strain of An. arabiensis it varied from $35.9 \%$ at day 2 after emergence to $28.6 \%$ at days $\geq 6$ with a maximum at days 3 and 4 (respectively 39.5 and $39.4 \%$ ). These differences were significant between days 2-3, days 45 and days $5-\geq 6$ (respectively $\mathrm{P}=0.043, \mathrm{P}=0.01$ and $\mathrm{P}=4 \cdot 10^{-4}$, by $\chi^{2}$ analysis) but not between days $3-4(\mathrm{P}=0.94)$. For the insectary strain it varied from $56.8 \%$ at day 2 after emergence to $77.8 \%$ at day 5 . These differences were significant between days 2-3-

\begin{tabular}{|c|c|c|c|c|c|c|}
\hline \multirow{2}{*}{$\begin{array}{l}\text { Age (in days) } \\
\text { of gorging mosquitoes }\end{array}$} & \multicolumn{3}{|c|}{ Wild strain of mosquito } & \multicolumn{3}{|c|}{ Insectary strain of mosquito } \\
\hline & Total & Engorged & Surviving & Total & Engorged & Surviving \\
\hline 2 & 1,065 & 382 & 235 & 435 & 247 & 86 \\
\hline 3 & 2,725 & 1,076 & 721 & 204 & 131 & 68 \\
\hline 4 & 2,325 & 915 & 581 & 150 & 93 & 61 \\
\hline 5 & 1,800 & 639 & 283 & 45 & 35 & 2 \\
\hline$\geq 6$ & 915 & 262 & 75 & 0 & - & - \\
\hline
\end{tabular}

Table I. - Total number of females Anopheles arabiensis, to which a blood meal was proposed using a membrane system, number of engorged females after ten minutes and number of engorged females surviving after eight days. 


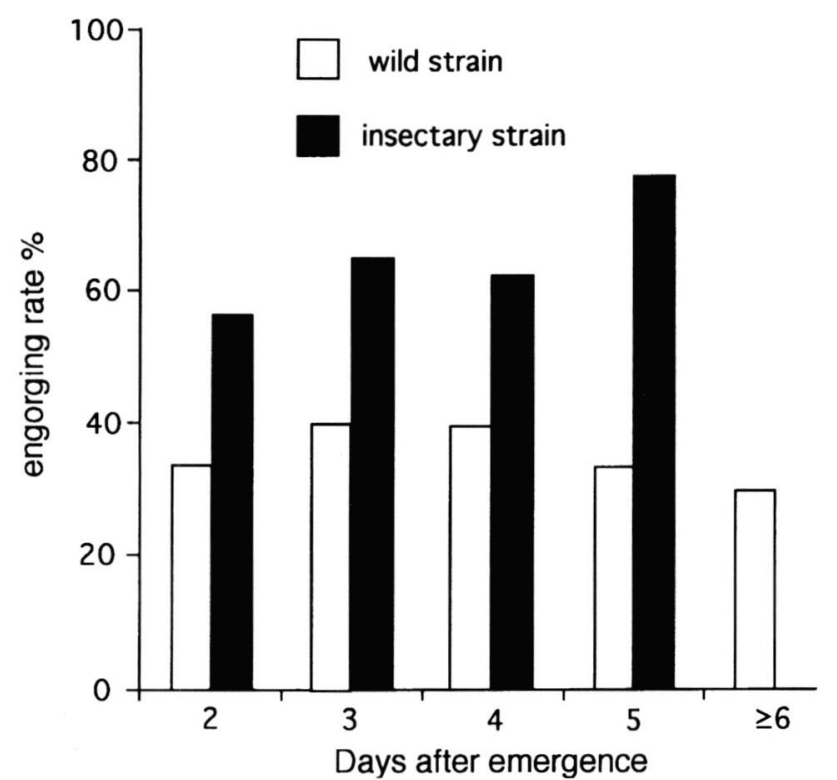

Fig. 1. - Engorgement rate of Anopheles arabiensis in relation to the age of gorging mosquitoes (in days after emergence) using a membrane feeding system.

4-5 ( $\mathrm{P}=0,03$ by $\chi^{2}$ analysis $)$ but were not significant between days 2-3, days 3-4 and days 4-5 (respectively $\mathrm{P}=0.08, \mathrm{P}=0.74$ and $\mathrm{P}=0.07)$. The differences between the two strains of mosquitoes were significant at day 2 , day 3 , day 4 and day 5 ( $\mathrm{P}<10^{-6}$ in each cases, by $\chi^{2}$ analysis).

The survival rate, measured eight days after the blood feeding, was dependant of the age of mosquitoes when they engorged (Table I and Fig. 2). For the wild

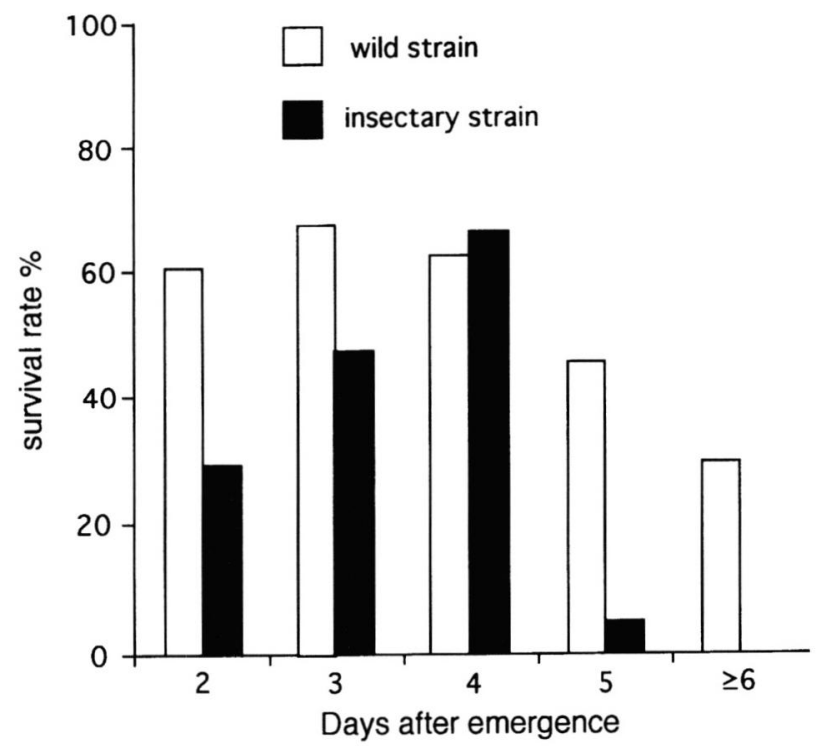

Fig. 2. - Survival rate eight days after the blood-feeding of engorged Anopheles arabiensis in relation to the age of gorging mosquitoes (in days after emergence) using a membrane feeding system.

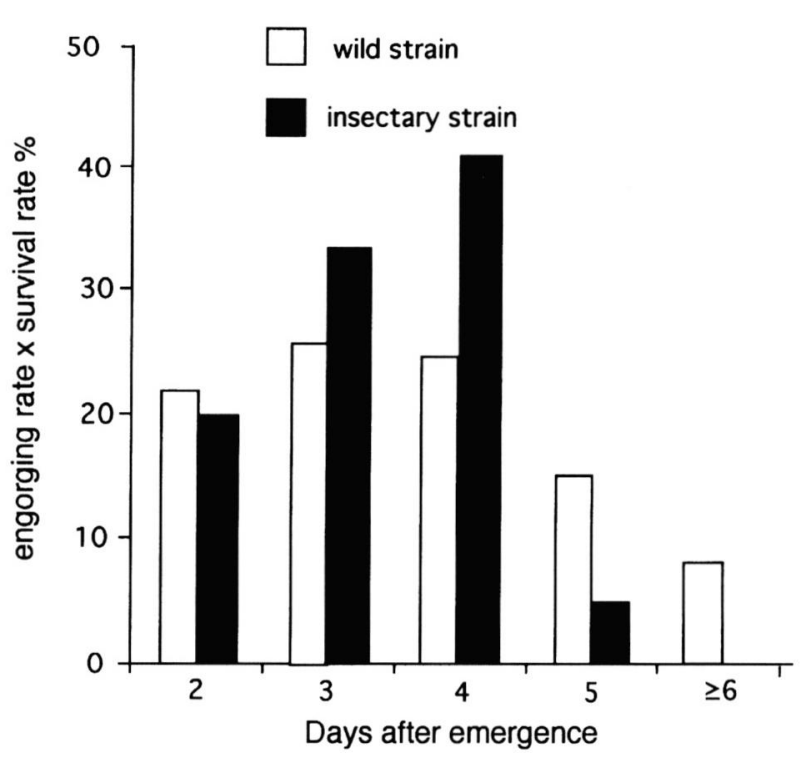

Fig. 3. - Product of the engorging rate by the survival rate eight days after the blood-feeding in relation to the age of gorging mosquitoes (in days after emergence). This is a combination of the Figures 1 and 2 .

strain of An. arabiensis it varied from $61.5 \%$ at day 2 after emergence to $28.8 \%$ at days $\geq 6$ with a maximum of $67.0 \%$ at days 3 . These differences were significant between days $4-5$ and days $5-\geq 6\left(\mathrm{P}<4.10^{-4}\right.$ in the two cases, by $\chi^{2}$ analysis) but not between days $2-3$ and days $3-4$ (respectively $\mathrm{P}=0.06$ and $\mathrm{P}=0.11$ ). For the insectary strain it varied from $34.8 \%$ at day 2 after emergence to $5.7 \%$ at day 5 with a maximum of $65.6 \%$ at days 4 . These differences were significant between days 2-3 and days 4-5 (respectively $\left.\mathrm{P}=10^{-3}, \mathrm{P}<10^{-4}\right)$ but not between days $3-4(\mathrm{P}=0.054)$. The differences between the two strains of mosquitoes were significant at day 2 , day 3 , and day $5\left(\mathrm{P}<10^{-6}\right.$, $\mathrm{P}=0.0009$ and $\mathrm{P}<10^{-5}$, respectively) but not at day 4 $(\mathrm{P}=0.77)$.

The combination of engorging rate and survival rate in a day by day analysis showed that the product of these two rates were maximum at days 3-4 after emergence for the wild strain and at day 4 for the insectary strain (Fig. 3).

\section{DISCUSSION}

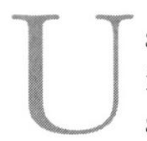
sing a membrane system the gorging rate of insectary strain was higher than those of wild strain. That result was attempted considering than insectary strain was partly selected for that capacity. In other respects the survival rate of engorged females of the insectary strain was lower than those of the wild strain. That might be related to a lower fitness of the insectary strain. 
Our results show that mosquitoes used for blood feeding using a membrane system would have to be aged of 3-4 days to maximize the output of experiments running up to eight days after the feeding, in particular for Plasmodium oocysts examination. It is interesting to note that mosquitoes aged 3-4 days develop more $P$. falciparum oocysts than older ones, possibly because the older mosquitoes digest their bloodmeals much faster (Lensen, 1996).

To use mosquitoes of 3-4 days would permit to optimize the membrane feeding system. This simple apparatus can be easily used in the field and is now involved on experiments on malaria transmission with special references to epidemiological studies on transmission immunity and for test of future transmissionblocking vaccines.

\section{ACKNOWLEDGEMENTS}

gratefully acknowledge SmithKline Beecham Africa International who have supported the work and - Doctor Yves Dutheil for his partnership. I would also like to thank Louis Barboza for invaluable technical assistance, Didier Fontenille and Martine LoustheRobert for comments on the manuscript.

\section{REFERENCES}

Cosgrove J.B. \& WoOD R.J. Probing and gorging responses of three mosquito species to a membrane feeding system at a range of temperatures. Journal of the American Mosquito Control Association, 1995, 11, 339-342.

Diop A. Elevage d'une souche d'Anopheles arabiensis Patton, 1905 (Diptera: Culicidae). Observations morphologiques, biologiques et étude de la sensibilité à la perméthrine. Mémoire de DEA de Biologie Animale n 73, 1995, Université Cheickh Anta Diop de Dakar, Sénégal.

LENSEN A.H.W. Infectivity of malarial parasites to mosquitoes: the interdependent roles of parasite, vector and host. Annals of Tropical Medicine and Parasitology, 1996, 90, 359-365.

Ponnudurai T., Lensen A.H.W., Van Gemert G.J.A., Bolmer M.G. \& Meuwissen J.H.E.T. Infectivity of cultured Plasmodium falciparum gametocytes to mosquitoes. Parasitology, 1989, 98, 165-173.

Rutledge L.C., WARD R.A. \& Gould D.J. Studies on the feeding response of mosquitoes to nutritive solutions in a new membrane feeder. Mosquito News, 1964, 24, 407-419.

WADE J.O. A new design of membrane feeder incorporating an electrical blood stirring device. Annals of Tropical Medicine and Parasitology, 1976, 70, 113-120.

Reçu le 18 septembre 1997 Accepté le 23 octobre 1997 